\title{
Heat strain, volume depletion and kidney function in California agricultural workers
}

\author{
Sally Moyce, ${ }^{1}$ Diane Mitchell, ${ }^{2}$ Tracey Armitage ${ }^{2}$ Daniel Tancredi, ${ }^{3}$ Jill Joseph, ${ }^{1}$ \\ Marc Schenker $^{2}$
}

- Additional material is

published online only. To view please visit the journal online (http://dx.doi.org/10.1136/ oemed-2016-103848).

${ }^{1}$ Betty Irene Moore School of Nursing, University of California, Davis, Sacramento, California, USA

${ }^{2}$ Department of Public Health Sciences, University of California, Davis, Davis, California, USA

${ }^{3}$ Department of Pediatrics, University of California, Davis, Davis, California, USA

\section{Correspondence to} Dr Sally Moyce, Betty Irene Moore School of Nursing, University of California, Davis, 4610 X Street, Sacramento, CA 95817, USA; sallymoyce@ gmail.com

Received 16 May 2016 Revised 23 November 2016 Accepted 19 December 2016 Published Online First 19 January 2017

\begin{abstract}
Background Agricultural work can expose workers to increased risk of heat strain and volume depletion due to repeated exposures to high ambient temperatures, arduous physical exertion and limited rehydration. These risk factors may result in acute kidney injury (AKI).

Methods We estimated AKI cumulative incidence in a convenience sample of 283 agricultural workers based on elevations of serum creatinine between preshift and postshift blood samples. Heat strain was assessed based on changes in core body temperature and heart rate. Volume depletion was assessed using changes in body mass over the work shift. Logistic regression models were used to estimate the associations of AKI with traditional risk factors (age, diabetes, hypertension and history of kidney disease) as well as with occupational risk factors (years in farm work, method of payment and farm task).
\end{abstract}

Results 35 participants were characterised with incident AKI over the course of a work shift (12.3\%). Workers who experienced heat strain had increased adjusted odds of AKI $(1.34,95 \% \mathrm{Cl} 1.04$ to 1.74). Piece rate work was associated with 4.24 odds of AKI (95\% Cl 1.56 to 11.52). Females paid by the piece had 102.81 adjusted odds of AKI $(95 \% \mathrm{Cl} 7.32$ to 1443.20).

Discussion Heat strain and piece rate work are associated with incident $A K I$ after a single shift of agricultural work, though gender differences exist. Modifications to payment structures may help prevent AKI.

\section{BACKGROUND}

Agricultural work exposes labourers to multiple environmental and occupational hazards that can contribute to adverse personal health outcomes. ${ }^{1}$ The work is most commonly seasonal, and during summer harvest, workers often spend long hours under direct sun, in intense heat, performing arduous physical labour. ${ }^{2}{ }^{3}$ In the Central Valley of California, which employs the majority of the estimated $450000+$ agricultural workers, summer temperatures regularly exceed $37.8^{\circ} \mathrm{C}\left(100^{\circ} \mathrm{F}\right) .^{4}$ California farm work is often labour-intensive and exposes workers to high ambient temperatures, varying levels of physical exertion and reliance on the worker to maintain sufficient hydration. ${ }^{5} 6$ Agricultural workers often report symptoms of heat-related illness, ${ }^{4} 7$ and in the USA they are estimated to be 20 times more likely to have a heat-related illness than workers in other

\section{What this paper adds}

- Occupational risks of agricultural work include heat strain and volume depletion in California agricultural workers, yet little is known about the effect of these risks on renal health.

- We find heat strain-but not volume depletion - to be associated with increased odds of acute kidney injury in agricultural workers after a day of work.

- Female workers paid by the amount of produce harvested (versus by the hour) have greatly increased odds of developing acute kidney injury.

- Heat strain and methods of payment are both important and modifiable occupational risk factors to renal health in agricultural workers.

industries. ${ }^{8}$ This suggests the need to better describe heat strain and volume depletion in this population, but these issues have rarely been studied among US farmworkers.

Of particular concern is the effect these working conditions may have on kidney function, particularly acute kidney injury (AKI). AKI is defined as a reduction in kidney function, often as a result of decreased renal blood flow. ${ }^{9}$ During periods of increased work load, renal perfusion progressively declines, ${ }^{10}$ and when coupled with high ambient temperatures and volume depletion, may be reduced by over $50 \% .{ }^{11}$ We are aware of two other studies in which AKI in agricultural workers has been examined. In an exploratory study, Santos et $a l^{12}$ estimated the cumulative incidence of AKI in agricultural workers in Brazil to be $18 \%$ after a single day of work, and to be associated with measures of volume depletion. García-Trabanino et $a l^{13}$ surveyed sugarcane workers in Nicaragua and found elevated serum creatinine levels in $25 \%$ of their sample, which was also significantly associated with high ambient temperature and volume depletion. In previous work, we estimated the cumulative incidence of AKI among agricultural workers in California to be nearly $12 \%$ after a single day of work. $^{14}$

To the best of our knowledge, no investigations have examined the association of heat strain and volume depletion with kidney function in agricultural workers in the USA, despite the occupational risks of physical labour in high ambient 
temperatures. We conducted this study to examine these associations in a sample of California agricultural workers.

\section{METHODS}

\section{Participants}

A convenience sample of 300 field workers was recruited from 15 farms in agricultural regions of California's Central Valley during the summer of 2014. To gain access to the work sites, we invited employers to participate in the study through outreach at local meetings and events, flyers, and word of mouth. About $30 \%$ of the farms we approached agreed to participate in the study. Bilingual, bicultural field staff recruited employees of the farms by explaining the purpose and protocol of the study in Spanish and obtained consent. Eligible participants were 18 years of age or older, worked in the fields for at least 6 hours per day, understood Spanish and were neither pregnant nor had any impediment to swallowing the ingestible sensor (such as current gastrointestinal illness or pacemaker). All eligible participants who volunteered were enrolled in the study for a single day of data collection and were given a small monetary gift of appreciation.

\section{Data collection}

Preshift measures

A brief, preshift questionnaire was administered orally in Spanish to assess participant eligibility and to collect demographic information. A capillary blood sample was taken and analysed using the handheld i-STAT point of care test to measure serum creatinine (Abbot Point of Care, Princeton, New Jersey, USA). The i-STAT measurements are traceable to isotope dilution mass spectrometry through the standard reference material SRM967. ${ }^{15}$ Weight was measured in a base layer of clothing (single layer over undergarments) using a Seca 874 medical scale, and height was measured without shoes using a Seca model 213 stadiometer (Seca GMBH, Hamburg, Germany). Field staff recorded base layer clothing to ensure that the participant wore the same garments for weighing after the shift. Participants swallowed a CorTemp HT15002 ingestible wireless temperature transmitter probe (HQInc, Palmetto, Florida, USA). The probe transmitted core temperature at $1 \mathrm{~min}$ intervals. ${ }^{16}$ Participants were fitted with a Polar T31 ECG heart rate transmitter around the thorax which transmitted heart rate measurements at $1 \mathrm{~min}$ intervals. Signals from the probe and the heart rate strap were recorded using a CorTemp HT150016 Data Recorder attached to their belts. All staff involved in data collection were trained and supervised, and all equipment was regularly calibrated to ensure accuracy.

\section{Postshift measures}

Following the work shift, 7-12 hours after ingestion of the CorTemp, workers returned to the data collection station and unloaded all external equipment. They were then reweighed in the same clothing as they wore during the preshift weight, prior to ingesting any water or refreshments. A postshift questionnaire was orally administered in Spanish to obtain information on health history and possible social and behavioural risk factors, such as a personal or family history of kidney disease and work history. A second capillary blood sample was obtained to document serum creatinine, and glycated haemoglobin (HbA1c) was measured using a Siemens DCA Vantage Analyzer (Siemens Healthcare Diagnostics, Tarrytown, New York, USA). A single blood pressure was obtained in the seated position using an automated blood pressure cuff (Omron blood pressure monitor, Lake Forest, Illinois, USA). Participants' BMI, blood pressure, diabetes risk status and blood creatinine level were shared with them at the conclusion of the day, and participants who had abnormal results were referred to local health clinics for follow-up care.

All study procedures were approved by the University of California, Davis Institutional Review Board.

\section{Outcome: AKI}

AKI during the work shift, defined by a specified increase in serum creatinine from the preshift to the postshift measure, was the primary outcome of interest. Using the recommended definition and stages of injury from the Kidney Disease: Improving Global Outcomes (KDIGO) group, ${ }^{9}$ AKI was defined as an increase of the postshift serum creatinine by $\geq 0.3 \mathrm{mg} / \mathrm{dL}$ or $\geq 1.5$ times the preshift creatinine. AKI staging was based on the following: stage $1(\geq 0.3 \mathrm{mg} / \mathrm{dL}$ or $1.5-1.9$ times preshift serum creatinine); stage 2 (2.0-2.9 times preshift serum creatinine) and stage 3 ( $\geq 3.0$ times preshift serum creatinine).

\section{Exposure: heat exposure and volume depletion}

Exposure variables explored were heat strain from a combination of work and environmental exposure and volume depletion. Acute heat strain was estimated by calculating the physiological strain index (PSI), ${ }^{17}$ based on readings collected throughout the work shift. Minute-by-minute readings of core body temperature and heart rate were preprocessed to remove physiologically impossible changes and then smoothed using loess estimation procedures and splines in SAS. ${ }^{18}$ A validated and reliable estimation of heat strain, PSI indicates the level of physiological strain on a scale from 0 to 10 . The formula uses a combination of heart rate (hr) and core temperature (in ${ }^{\circ} \mathrm{C}$ ) to estimate the effect of temperature and workload, as specified in the following equation: ${ }^{17}$

$$
\begin{aligned}
\text { PSI }= & 5 \times(\text { peak core temp }- \text { base core temp }) /(39.5 \\
& - \text { base core temp })+5 \times(\text { peak hr }- \text { base hr }) /([220-\text { age }] \\
& - \text { base hr }),
\end{aligned}
$$

with input value derived from the preprocessed, smoothed heart rate and temperature minute-by-minute traces. Based on other studies using PSI to calculate heat strain, participants in our sample who had PSI $\geq 7.5$ were classified as experiencing heat strain. ${ }^{19}$

Volume depletion was assessed via per cent change in body mass by comparing preshift and postshift body weights and dividing by the preshift body weight (([postshift-preshift]/preshift) $\times$ 100). In field conditions, body mass change is considered the most accurate method for estimating hydration status, ${ }^{20} 21$ and $1 \mathrm{~kg}$ of body weight represents $1 \mathrm{~L}$ of body fluid. ${ }^{22}$ Recommendations of the National Institute of Occupational Safety and Health (NIOSH) to prevent heat-related illness among agricultural workers state that workers should not lose more than $1.5 \%$ body mass over the course of a work shift. ${ }^{23}$

\section{Covariates}

Variables thought to be associated with AKI were selected a priori based on a review of the literature and feasibility of collecting data in the field. Demographic variables included sex (male vs female), age (continuous) and level of education (none/ don't know, less than high school, some high school, or graduated high school). Clinical data were also obtained. Estimated glomerular filtration rate (eGFR) was calculated using preshift serum creatinine based on the Chronic Kidney Disease 
Epidemiology Collaboration (CKD-EPI) equation $^{24}$ and categorised as $\geq 90 \mathrm{~mL} / \mathrm{min} / 1.732, \geq 60$ to $<90 \mathrm{~mL} / \mathrm{min} / 1.73^{2}$ or $<60 \mathrm{~mL} / \mathrm{min} / 1.73^{2}$. Body mass index (BMI) was calculated from preshift height and weight measurements $(\mathrm{BMI}=$ weight in $\mathrm{kg} /$ height in metres squared), and classified based on WHO recommendations $^{25}$ as normal weight $(\mathrm{BMI}<25)$, overweight (BMI 25.0-29.9) or obese (BMI $\geq 30)$. Diabetes status was defined by standard categories of $\mathrm{HbA} 1 \mathrm{c}:^{26}$ no diabetes (HbA1c $<5.7 \%$ and no self-reported antidiabetic medications), prediabetes (HbA1c $5.7-6.4 \%)$ or diabetes $(\mathrm{HgA} 1 \mathrm{c} \geq 6.5 \%$ or self-reported diabetes diagnosis or self-reported antidiabetic medications). Seated blood pressure was categorised as recommended by the Joint Commission: ${ }^{27}$ normal blood pressure $(<120 / 80$ and no self-reported antihypertensives), prehypertension (120-139/8089 ), or hypertension ( $\geq 140 / 90$ or taking antihypertensives). Self-reported information on personal or family history of kidney disease (yes vs no) was collected. Variables related to occupation included years in agricultural work (continuous), how the worker was paid (hourly, by the piece (or amount of produce harvested) or salary), and the farm task they engaged in most during that day (picking, hoeing, irrigation, packing/ sorting/planting, hand pruning/weeding or other (eg, vehicle maintenance or supervising)).

\section{Statistical analysis}

Descriptive statistics were calculated for the outcome and potential risk factors, in pooled models and stratified by sex. Differences between males and females were tested using $\chi^{2}$ tests. We determined AKI classification using the three stages of AKI. We then estimated the association of categories of per cent change in body mass (no change, gained any weight, lost $<1.5 \%$, lost $\geq 1.5 \%$ ) and heat strain (PSI $<7.5$ vs $\mathrm{PSI} \geq 7.5$ ) with AKI categories.

In regression models, we dichotomised AKI as 'any' versus 'none'. Logistic regression models assessed the associations between AKI and predictor variables. Because of concerns that sex might modify the effects of interest, we fit models stratified by sex in addition to pooled models. To aid in interpretation of the main effects in models which included interaction terms, we centred the PSI at a selected reference point (PSI=4) and subtracted 4 from each value of PSI. We defined heat strain as a continuous variable based on the PSI. Our first model estimated the age-adjusted association of body mass change and heat strain on AKI. The second model added physiological or traditional risk factors, including weight class, diabetes status, hypertension status, and personal or family history of kidney disease. The final model added occupational risk factors, including years in farm work, payment method and farm task. We tested for effect modification of significant predictors (heat strain $\times$ volume depletion, piece rate $\times$ heat strain, piece rate $\times$ volume depletion, heat strain $\times$ obesity and piece rate $\times$ obesity). The Akaike and Bayes information criteria are model goodness of fit measures that incorporate a complexity penalty in favour of parsimonious models, with smaller values indicating better model fit. We report these measures for all models and used them to select the final model, with preference going to Akaike in case of conflicting results.

Investigator beliefs about possible causal linkages were encoded using directed acyclic graphs, to develop a parsimonious set of candidate covariates (see online supplementary figure). Covariates were also screened for variation. Those without sufficient variation were dropped (eg, baseline eGFR). For some categorical variables, levels were combined to increase the precision of estimates involving these factors. For example, diabetes was collapsed to $\mathrm{HbA} 1 \mathrm{c}<5.7$ vs $\geq 5.7$. Farm task was also collapsed to picking versus other. Participants with missing values for critical variables $(n=17)$ were dropped (ie, we performed a complete case analysis). A total of 300 participants were enrolled in the study. Five participants were missing either preshift or postshift creatinine measures, and an additional 12 were missing variables required for calculating heat strain, and the final analyses therefore included 283 participants $(94 \%$ of enrollees).

All analyses were conducted using STATA V.12 (Stata Corp LP, College Station, Texas, USA).

\section{RESULTS}

Our sample consisted of 182 males and 101 females, and the majority of the participans were from Mexico (93.6\%). The mean age was 38.6 years (SD 12.4). Most participants were overweight $(42 \%)$ or obese $(39.6 \%)$ and were prehypertensive (45.7\%) or hypertensive (31.9\%). Most had eGFR $\geq 90 \mathrm{~mL} / \mathrm{min} /$ $1.73^{2}(92.2 \%)$, were not patients with diabetes or prediabetes (78.2\%), and had no personal or family history of kidney disease $(75.3 \%)$. The mean maximum temperature (sustained for at least $3 \mathrm{~min}$ ) was $38.0^{\circ} \mathrm{C}$ (SD 0.4 ), and the mean maximum heart rate (sustained for at least $3 \mathrm{~min}$ ) was $130 \mathrm{bpm}$ (SD $27.7 \mathrm{bpm}$ ). Statistically significant differences between the two sexes are shown in table 1 . Overall, men reported higher levels of education than women. Men also had higher rates of prehypertension or hypertension than women $(49.7 \%$ vs $38.6 \%$ and $37.0 \%$ vs $22.8 \%$, respectively). Men reported more years working in agriculture (12.4 vs 9.6 years). There were also differences in the payment method, with $30.8 \%$ of men being paid by the piece versus $19.8 \%$ of women (table 1 ).

Using changes in serum creatinine from preshift measures to postshift measures, 31 participants $(11.0 \%)$ met KDIGO criteria for stage 1 AKI (table 2). An additional four participants (1.3\%) met criteria for stage 2 AKI. Stratified by sex, 22 males (12.1\%) and 13 females (12.9\%) met criteria for AKI. Among men, 10 experienced heat strain, as estimated by PSI $\geq 7.5$, and 3 of those met criteria for AKI. No women experienced heat strain. Additionally, most of the sample experienced loss of body mass during the shift, but most did not lose more than recommended by OSHA. For example, $118(64.8 \%)$ of men and $53(52.5 \%)$ of women lost $<1.5 \%$ body mass. However, five of the men and two of the women who lost $\geq 1.5 \%$ body mass met criteria for AKI. There were no statistically significant unadjusted associations of AKI with either heat strain or the change in body mass classification.

Table 3 shows the results of logistic regression models. In the age-adjusted and sex-adjusted model, heat strain was associated with 1.29 adjusted odds (OR) of AKI (95\% CI 1.03 to 1.61). In this model, stratified by sex, the association among men was significant (OR 1.31, 95\% CI 1.01 to 1.70 ), but not among women. In the model adding physiological characteristics, the association of heat strain on AKI was virtually unchanged (OR $1.34,95 \%$ CI 1.03 to 1.65$)$. Obesity was significantly associated with AKI (OR $0.29,95 \%$ CI 0.10 to 0.82 ). In the stratified model, men who were overweight or obese had reduced odds of AKI (overweight OR 0.29 , 95\% CI 0.08 to 0.97 ; obese OR $0.25,95 \%$ CI 0.07 to 0.94$)$. There were no statistically significant associations among females. The addition of occupational characteristics in the final model did not appreciably change previous associations. However, piece rate work was associated with 4.24 adjusted odds of AKI (95\% CI 1.56 to 11.52). In stratified models, this association was not significant among men. Among females, the adjusted odds of AKI rose to 102.81 
Table 1 Sample characteristics $(n=283)$

\begin{tabular}{|c|c|c|c|c|c|c|c|}
\hline & \multicolumn{2}{|c|}{ Male $(n=182)$} & \multicolumn{3}{|c|}{ Female $(n=101)$} & \multicolumn{2}{|c|}{ Total sample } \\
\hline & $\mathbf{n}$ & Per cent & $\mathbf{n}$ & Per cent & & $\mathbf{n}$ & Per cent \\
\hline Age (mean, SD) & 38.4 & 13.0 & 39.0 & 11.5 & & 38.6 & 12.4 \\
\hline \multicolumn{8}{|l|}{ Country of origin } \\
\hline USA & 12 & 6.6 & 3 & 3.0 & & 15 & 5.3 \\
\hline Mexico & 167 & 91.8 & 98 & 97.0 & & 265 & 93.6 \\
\hline El Salvador & 3 & 1.7 & 0 & 0.0 & & 3 & 1.1 \\
\hline Level of education & & & & & * & & \\
\hline No education/don't know & 8 & 4.4 & 1 & 0.9 & & 9 & 3.2 \\
\hline Less than high school & 107 & 58.8 & 80 & 79.2 & & 187 & 66.1 \\
\hline Some high school & 33 & 18.1 & 11 & 11.0 & & 44 & 15.5 \\
\hline Graduated high school & 34 & 18.7 & 9 & 8.9 & & 43 & 15.2 \\
\hline \multicolumn{8}{|l|}{ Baseline eGFRt } \\
\hline$\geq 90 \mathrm{~mL} / \mathrm{min} / 1.73^{2}$ & 165 & 90.7 & 96 & 95.0 & & 261 & 92.2 \\
\hline$\geq 60$ to $<90 \mathrm{~mL} / \mathrm{min} / 1.73^{2}$ & 15 & 8.8 & 5 & 5.0 & & 21 & 7.4 \\
\hline$<60 \mathrm{~mL} / \mathrm{min} / 1.73^{2}$ & 1 & 0.5 & 0 & 0.0 & & 1 & 0.4 \\
\hline \multicolumn{8}{|l|}{ BMI‡ } \\
\hline Normal weight $(<25)$ & 39 & 21.4 & 13 & 12.9 & & 52 & 18.4 \\
\hline Overweight (25-30) & 74 & 40.7 & 45 & 44.6 & & 119 & 42.0 \\
\hline Obese $(>30)$ & 69 & 38.0 & 43 & 42.6 & & 112 & 39.6 \\
\hline \multicolumn{8}{|l|}{ Diabetes§ } \\
\hline No diabetes ( $\mathrm{HbA} 1 \mathrm{c}<5.7 \%)$ & 139 & 79.4 & 76 & 76.0 & & 215 & 78.2 \\
\hline Prediabetes (HbA1c 5.7-6.4\%) & 19 & 10.9 & 14 & 14.0 & & 33 & 12.0 \\
\hline Diabetes $(\mathrm{HbA} 1 \mathrm{c} \geq 6.5 \%)$ & 17 & 9.7 & 10 & 10.0 & & 27 & 9.8 \\
\hline Blood pressureף & & & & & * & & \\
\hline Normal blood pressure $(<120 / 80)$ & 24 & 13.3 & 39 & 38.6 & & 63 & 22.3 \\
\hline Prehypertensive (120-139/80-89) & 90 & 49.7 & 39 & 38.6 & & 129 & 45.7 \\
\hline Hypertension $(\geq 140 / 90)$ & 67 & 37.0 & 23 & 22.8 & & 90 & 31.9 \\
\hline \multicolumn{8}{|l|}{ History of kidney disease } \\
\hline None & 140 & 76.9 & 73 & 72.3 & & 213 & 75.3 \\
\hline Personal history & 10 & 5.5 & 4 & 4.0 & & 14 & 4.9 \\
\hline Family history & 32 & 17.6 & 24 & 23.8 & & 56 & 19.8 \\
\hline Years in agricultural work (mean, SD) & 14.6 & 12.4 & 11.5 & 9.6 & * & 14 & 11.6 \\
\hline Payment method & & & & & * & & \\
\hline Hourly & 120 & 65.9 & 79 & 78.2 & & 199 & 70.3 \\
\hline Piece rate & 56 & 30.8 & 20 & 19.8 & & 76 & 26.9 \\
\hline Salary & 6 & 3.3 & 2 & 2.0 & & 8 & 2.8 \\
\hline \multicolumn{8}{|l|}{ Farm task } \\
\hline Picking & 58 & 31.9 & 24 & 23.8 & & 82 & 29.0 \\
\hline Hoeing & 13 & 7.1 & 15 & 14.9 & & 28 & 9.9 \\
\hline Irrigation & 30 & 16.5 & 0 & 0.0 & & 30 & 10.6 \\
\hline Packing/sorting/planting & 7 & 3.8 & 27 & 26.7 & & 34 & 12.0 \\
\hline Hand pruning/weeding & 24 & 13.2 & 31 & 30.7 & & 55 & 19.4 \\
\hline Other* * & 50 & 27.5 & 4 & 4.0 & & 54 & 19.1 \\
\hline Maximum core temperaturet† (mean, SD) & 38.0 & 0.4 & 38.0 & 0.3 & & 38.0 & 0.4 \\
\hline Maximum heart rate†† (mean, SD) & 129.6 & 28.8 & 132.4 & 25.1 & & 130.6 & 27.6 \\
\hline \multicolumn{8}{|c|}{$\begin{array}{l}\text { *Significant at } p<0.05 \text { based on } \chi^{2} \text { tests or t-tests comparing sexes. } \\
\text { teGFR, based on CKD-EPI equation. } \\
\text { †BMI }\left(\mathrm{kg} / \mathrm{m}^{2}\right) \text { categorized based on WHO classification. } \\
\S \text { HbA1c from capillary blood sample. } \\
\text { IBlood pressure based on JNC7 categories. } \\
\text { **'Other' includes supervising staff, machinery repair, shoveling dirt or fumigating. } \\
\text { ††Maximum levels sustained for } 3 \text { min or longer during work shift. } \\
\text { BMI, body mass index; eGFR, estimated glomerular filtration rate; HbA1c, glycated haemoglobin. }\end{array}$} \\
\hline
\end{tabular}

(95\% CI 7.32 to 1443.20 ). Additionally, there was a statistically significant association of years in agricultural work to AKI among females (OR 1.12, 95\% CI 1.01 to 1.24 ; results from stratified models available in online supplementary files). We modelled BMI as a continuous variable and found an inverse linear association with AKI: for every one-point increase in BMI, the odds of AKI went down 0.09 ( $p<0.05$, results not shown).

In subsequent pooled models, we added the interaction terms. None were statistically associated with AKI, nor did the 


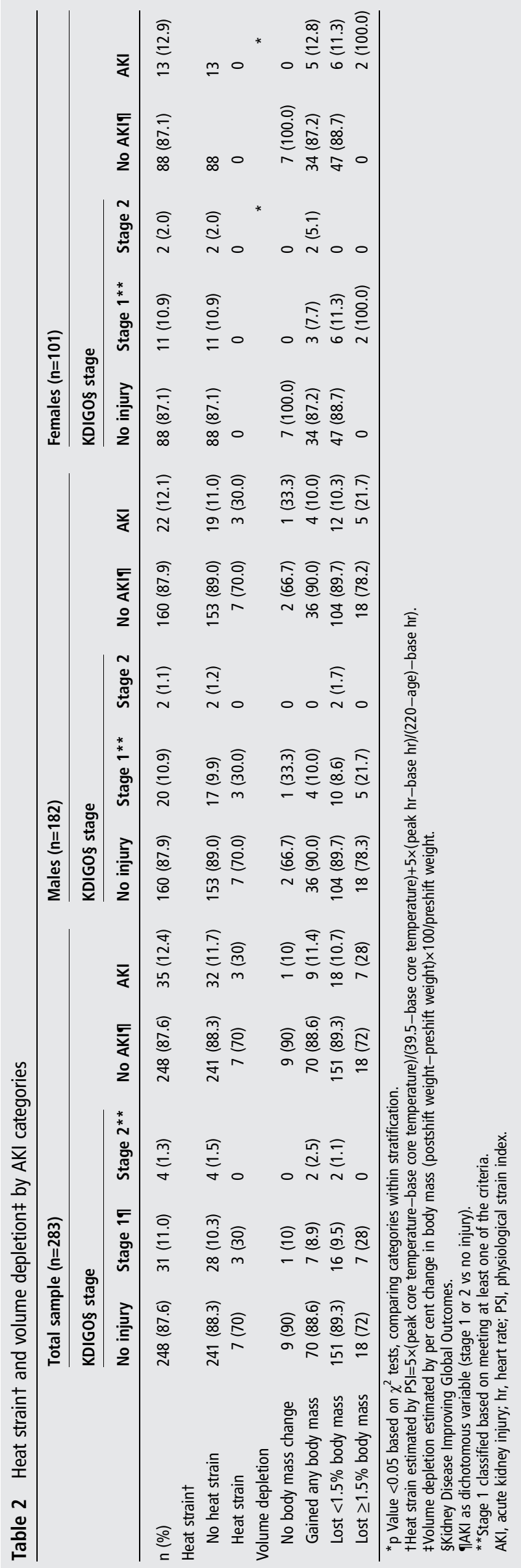

additions appreciably change the estimations. Additionally, the model-fit statistics did not improve with the addition of the interaction terms (results not shown).

\section{DISCUSSION}

Incident AKI occurred in 35 participants (12.3\%) in our sample of 283 California agricultural workers in the summer of 2014, in 22 of the 182 males (12.1\%) and 13 of 101 females (12.9\%). In males, heat strain as estimated by PSI was associated with increased odds of incident AKI. In females, heat strain measurement was not associated with AKI, but occupational factors such as years in agricultural work and being paid by the piece were associated with AKI. While manifested differently between the two sexes, these findings together suggest that incident AKI is an occupational risk factor of agricultural work.

The association of heat strain and AKI is not surprising, given that occupational heat strain has been associated with increased risk of renal insufficiency. ${ }^{28} 29$ In particular, heat strain has been named as one of the potential risk factors for the development of a chronic kidney disease identified among agricultural workers in Central America, India and Sri Lanka. ${ }^{30-34}$ Moreover, heat exposure has been linked to AKI in other studies of otherwise healthy individuals such as athletes ${ }^{35} 36$ and military recruits. ${ }^{37}$

Given the high ambient temperatures in the Central Valley and the strenuous nature of agricultural work, our estimates of heat strain using the PSI were surprisingly lower than we expected, particularly among women, none of whom experienced heat strain. Other researchers have found agricultural work to be associated with high levels of heat strain both in the USA and in other countries. ${ }^{3} 6738-42$ The Central Valley has low levels of humidity, which may allow workers to maintain cooler body temperatures than in other agricultural areas with high humidity. In addition, California is progressive in its prevention of heat-related illness through regulations of the state Occupational Safety and Health Administration (Cal-OSHA). Under Cal-OSHA requirements, farmers are required to provide heat illness prevention training for workers and offer regular breaks to cool off and rehydrate (Cal-OSHA Heat Illness Regulation 3395). Despite research that suggests workers do not remember the information provided in the trainings and do not take recommended breaks, ${ }^{4}{ }^{43}$ our estimates of heat strain indicate that workers in our sample do not experience high levels of heat strain. This may be related to the different farm tasks performed, suggesting that not all farm work is strenuous. For example, the majority of the women were involved in packing or weeding, which is less strenuous than picking. However, the finding that heat strain in males was statistically associated with incident AKI suggests that agricultural workers who do experience high levels of heat strain are at risk of adverse renal effects. Fortunately, current research into simple interventions, such as the use of backpack water reservoirs and the enforcement of rest periods during agricultural work, has had an effect on symptoms of heat strain ${ }^{44}$ and may provide a potential means of protecting the kidneys.

The finding that women are affected differently by occupational exposures than men may be expected due to known gender differences in agricultural work. However, we were surprised to see that the occupational risk factors of years in agricultural work and payment method were associated with AKI in women in our sample. Studies of women's experiences in agricultural work have documented the risk of sexual harassment or assault, which often occurs around bathroom facilities. ${ }^{45} 46$ Women may tend to limit drinking or eating during their work 
Table 3 Association of risk factors with acute kidney injuryt based on logistic regression $(n=283)$

\begin{tabular}{|c|c|c|c|c|c|c|c|c|c|c|c|c|}
\hline & \multicolumn{4}{|c|}{$\begin{array}{l}\text { Age-adjusted and sex-adjusted } \\
\text { model }\end{array}$} & \multicolumn{4}{|c|}{$\begin{array}{l}\text { Model adding physiological } \\
\text { factors }\end{array}$} & \multicolumn{4}{|c|}{$\begin{array}{l}\text { Model adding occupational } \\
\text { factors }\end{array}$} \\
\hline & AOR & $95 \% \mathrm{Cl}$ & p Value & & AOR & $95 \% \mathrm{Cl}$ & p Value & & AOR & $95 \% \mathrm{Cl}$ & p Value & \\
\hline Per cent body mass lost $¥$ & 0.66 & 0.42 to 1.06 & 0.08 & & 0.66 & 0.41 to 1.06 & 0.09 & & 0.7 & 0.42 to 1.17 & 0.18 & \\
\hline Heat strain§ & 1.29 & 1.03 to 1.61 & 0.03 & * & 1.34 & 1.03 to 1.65 & 0.03 & * & 1.34 & 1.04 to 1.74 & 0.02 & * \\
\hline Age in years & 0.99 & 0.97 to 1.02 & 0.65 & & 0.99 & 0.95 to 1.02 & 0.42 & & 0.98 & 0.94 to 1.02 & 0.34 & \\
\hline \multicolumn{13}{|l|}{ Sex } \\
\hline Male (reference) & - & - & - & & - & - & - & & - & - & - & \\
\hline Female & 1.46 & 0.65 to 3.26 & 0.36 & & 1.44 & 0.60 to 3.44 & 0.41 & & 2.12 & 0.80 to 5.63 & 0.13 & \\
\hline \multicolumn{13}{|l|}{ BMIף } \\
\hline Normal weight $(<25)$ (reference) & & & & & - & - & - & & - & - & - & \\
\hline Overweight (25-30) & & & & & 0.39 & 0.15 to 1.00 & 0.05 & & 0.41 & 0.15 to 1.09 & 0.07 & * \\
\hline Obese $(>30)$ & & & & & 0.29 & 0.10 to 0.82 & 0.02 & * & 0.32 & 0.11 to 0.96 & 0.04 & * \\
\hline \multicolumn{13}{|l|}{ Diabetes** } \\
\hline $\mathrm{HbA1c}<5.7 \%$ (reference) & & & & & - & - & - & & - & - & - & \\
\hline $\mathrm{HbA} 1 \mathrm{c} \geq 5.7 \%$ & & & & & 2.45 & 0.93 to 6.46 & 0.07 & & 2.63 & 0.93 to 7.41 & 0.07 & \\
\hline \multicolumn{13}{|l|}{ Blood pressuret† } \\
\hline Normal blood pressure $(<120 / 80)$ (reference) & & & & & - & - & - & & - & - & - & \\
\hline Prehypertensive (120-139/80-89) & & & & & 0.64 & 0.24 to 1.70 & 0.37 & & 0.73 & 0.26 to 2.06 & 0.56 & \\
\hline Hypertension $(\leq 140 / 90)$ & & & & & 0.74 & 0.24 to 2.23 & 0.59 & & 0.94 & 0.29 to 2.99 & 0.91 & \\
\hline \multicolumn{13}{|l|}{ History of kidney disease } \\
\hline None (reference) & & & & & - & - & - & & - & - & - & \\
\hline Personal or family history & & & & & 1.35 & 0.58 to 3.13 & 0.49 & & 1.64 & 0.680 to 3.98 & 0.27 & \\
\hline Years in agricultural work & & & & & & & & & 1.03 & 0.98 to 1.08 & 0.21 & \\
\hline \multicolumn{13}{|l|}{ Payment method } \\
\hline Hourly/salary (reference) & & & & & & & & & - & - & - & \\
\hline Piece rate & & & & & & & & & 4.24 & 1.56 to 11.52 & 0.01 & * \\
\hline \multicolumn{13}{|l|}{ Farm task } \\
\hline Picking & & & & & & & & & 1.1 & 0.41 to 2.92 & 0.86 & \\
\hline Other (reference) $\ddagger \ddagger$ & & & & & & & & & - & - & - & \\
\hline \multicolumn{13}{|l|}{ Model fit statistics } \\
\hline $\mathrm{AIC}$ & 212.6 & & & & 214.97 & & & & 207.84 & & & \\
\hline $\mathrm{BIC}$ & 230.8 & & & & 255.07 & & & & 258.88 & & & \\
\hline \multicolumn{13}{|l|}{ 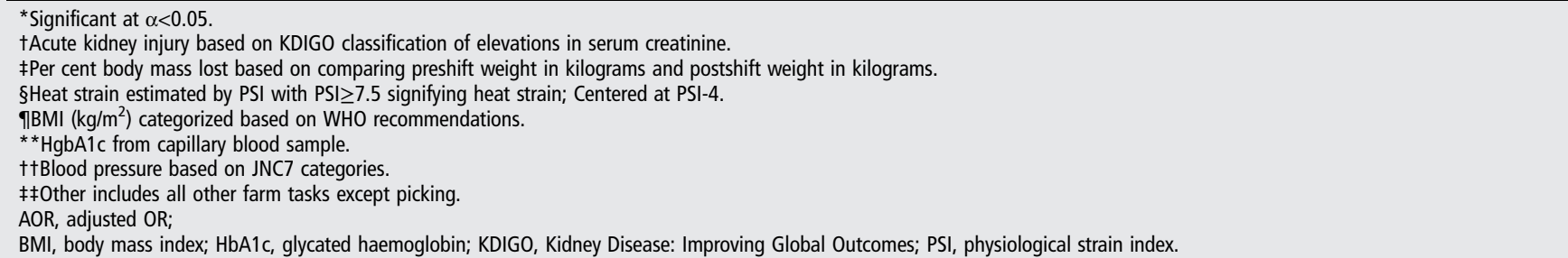 } \\
\hline
\end{tabular}

shift to reduce their need to use these facilities, or may delay trips to the bathroom during the work day out of fear for their safety. In a study of women in India who experienced heat stress at work, researchers found that delayed urination among women was associated with increased risk of urinary tract infection and AKI. ${ }^{47}$ The association of years of agricultural work and AKI among women in our sample could suggest that chronic delayed urination may increase the risk of AKI. ${ }^{48}$ Our finding that workers paid by the piece had higher odds of AKI requires further investigation, particularly because our sample size yielded imprecise estimates, and wide CIs may be attributed to the low numbers of women who experienced AKI and were paid by the piece $(n=9)$. Piece rate work incentivises the worker to work harder and to take fewer breaks by financially rewarding higher productivity. ${ }^{49}$ Women who are paid by the piece may have an extra incentive to not visit the bathroom during the work shift, and piece rate work is associated with other poor health outcomes, including higher rates of accidents, ${ }^{50}$ musculoskeletal injury ${ }^{51-53}$ and risk-taking among workers. ${ }^{54}$ The independent association of piece rate work on AKI among women in our models suggests that piece rate work is a marker of conditions potentially damaging to kidney function, and that this mechanism is separate from heat strain or hydration status. Alternatively, piece rate work may be a better measure of the factors suspected to be involved in the development of AKI, which could explain the associations found here. In either case, modifications to the pay structure may help prevent AKI in agricultural workers.

While not a risk factor for AKI in our estimations, the majority of workers in our sample experienced volume depletion after an agricultural work shift as measured by change in body mass. Other estimates of fluid intake among agricultural workers suggest that the amount of water workers drink is not sufficient to replace fluids and electrolytes lost during the work shift, ${ }^{6}$ as many do not believe they are at risk for injury and do not adequately rehydrate. ${ }^{5}$ In addition, agricultural workers often distrust water supplied by 
employers, and do not bring enough of their own water to adequately hydrate during the day. ${ }^{43}$ However, the lack of association of volume depletion to AKI was surprising, given the above findings. Volume depletion has been posited as a mechanism for AKI and potentially further damage. ${ }^{55-57}$ Recent research suggests that chronic volume depletion leads to sustained release of vasopressin and increased uric acid levels, which may precipitate longterm damage to the kidneys. ${ }^{58} 59$ Our findings suggest that heat strain, not volume depletion, may be a more concerning risk factor in this population.

Surprisingly, we found an inverse dose-response relationship of body weight and AKI, where those classified as overweight had lower odds of developing AKI than those classified as normal weight. Obesity is generally accepted as a risk factor for the development of AKI; ${ }^{60}$ however, one study found that increased BMI is associated with decreased mortality from AKI in elderly surgical patients. ${ }^{61}$ The inverse relationship of obesity to AKI in our results is puzzling, though potentially explained by the fact that the addition of occupational characteristics attenuated the relationship of BMI to AKI. If AKI is a result of agricultural work, it is conceivable that obese participants modified or reduced their workload, thus reducing their risk of AKI.

\section{Limitations}

Limitations of our study include using a convenience sample by approaching employers to recruit participants at their work sites. Farms that were willing to allow a team of researchers to measure hydration and heat strain may be more likely to protect their workers, for example, stopping work earlier in the day under conditions of extreme heat, and adhering to state regulations for high heat protection. Recruitment of agricultural workers in California is difficult, due to their mobile lifestyle and concerns regarding documentation status, and recruiting a convenience, employer-based sample was the only way to gain access to workers during the course of their work day. A second limitation is the calculation of the PSI variable, used to estimate heat strain. Owing to limitations of our equipment, some of the measurements of heart rate and core body temperature were missing, which may have affected our estimates. We were able to account for this by working with a team of exercise physiologists, clinicians and statisticians to provide robust and accurate estimations. Finally, estimates of AKI based on KDIGO guidelines use a 24-hour measure of urine output, which is not feasible in the field setting. Additionally, elevations in serum creatinine in our sample are potentially related to muscle injury (rhabdomyolysis), which we were unable to assess in our study. Despite these limitations, we were able to estimate the incidence of AKI over the course of a work shift and test associations between traditional and occupational risk factors.

Agricultural workers are a vulnerable population, often undocumented, living in poverty, culturally and linguistically isolated, with reduced worker protections. ${ }^{52} 62$ The development of AKI over the course of a work shift in this population may lead to further kidney damage, including chronic kidney disease, particularly because it is unlikely that workers know they are damaging their kidneys while working in the fields. Further research is needed to evaluate the long-term consequences of repeated AKI among farmworkers. While occupational regulations are in place to protect workers from heat-related illness, we have shown that workers who experience high levels of heat strain and who are paid by the piece are at increased risk. Fortunately, these risk factors are both modifiable, and incident AKI associated with heat strain and piece rate work may be prevented.
Correction notice This paper has been updated since it first published online. The article type has been changed.

Contributors All authors contributed to the work of this manuscript. SM conceptualised and oversaw the research and drafted the manuscripts. DM oversaw data collection and data management. TA assisted with data analysis. DT oversaw statistical analysis. JJ contributed to study design and manuscript preparation. MS oversaw all study procedures.

Funding The work reported here was supported by dissertation grants from the UC Global Health Initiative, the Health Initiative of the Americas, and the Western Center for Agricultural Safety and Health.

Competing interests None declared.

Patient consent Obtained.

Ethics approval All study procedures were reviewed and approved by the Institutional Review Board at the University of California, Davis.

Provenance and peer review Not commissioned; externally peer reviewed.

\section{REFERENCES}

1 Mobed K, Gold EB, Schenker M. Occupational health problems among migrant and seasonal farm workers. West J Med 1992;157:367.

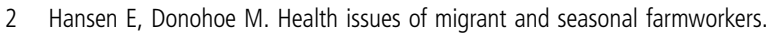
J Health Care Poor Underserved 2003:14:153-64.

3 Jackson LL, Rosenberg HR. Preventing heat-related illness among agricultural workers. J Agromedicine 2010;15:200-15.

4 Stoecklin-Marois M, Hennessy-Burt T, Mitchell D, et al. Heat-related illness knowledge and practices among California hired farm workers in The MICASA Study. Ind Health 2013;51:47-55.

5 Delgado Cortez 0 . Heat stress assessment among workers in a Nicaraguan sugarcane farm. Glob Health Action 2009;2:65-70.

6 Crowe J, van Wendel de Joode B, Wesseling C. A pilot field evaluation on heat stress in sugarcane workers in Costa Rica: what to do next? Glob Health Action 2009;2:71-80.

7 Fleischer NL, Tiesman HM, Sumitani J, et al. Public health impact of heat-related illness among migrant farmworkers. Am J Prev Med 2013;44:199-206.

8 Wilk VA. The occupational health of migrant and seasonal farmworkers in the United States. ERIC, 1986.

9 Kidney Disease Improving Global Health Outcomes (KDIGO) Working Group. Definition and classification of acute kidney injury. Kidney Int 2012;2:(Suppl 2):19-36.

10 Bakonska-Pacon E. Creatinine clearance and 24-hour creatinine excretion profile in the urine of people after physical exercises. Biol Sport 2006;23:157-70.

11 Smith J, Robinson S, Pearcy M. Renal responses to exercise, heat and dehydration. J Appl Physiol 1952;4:659-65.

12 Santos UP, Zanetta DMT, Terra-Filho M, et al. Burnt sugarcane harvesting is associated with acute renal dysfunction. Kidney Int 2015;87:792-9. http://www. nature.com/articles/ki2014306 http://dx.doi.org/10.1038/ki.2014.306

13 García-Trabanino R, Jarquín E, Wesseling C, et al. Heat stress, dehydration, and kidney function in sugarcane cutters in El Salvador-a cross-shift study of workers at risk of Mesoamerican nephropathy. Environ Res 2015;142:746-55. http://www. sciencedirect.com/science/article/pii/S0013935115300281 http://dx.doi.org/10.1016/ j.envres.2015.07.007

14 Moyce S, Joseph J, Tancredi D, et al. Cumulative incidence of acute kidney injury in California's agricultural workers. J Occup Environ Med 2016:58:391-7.

15 Shephard MD. Point-of-care testing and creatinine measurement. Clin Biochem Rev 2011;32:109-14.

16 Engels HJ, Yarandi HN, Davis JE. Utility of an ingestible capsule for core temperature measurements during body warming. J Exerc Physiol Online 2009;12:1.

17 Moran DS, Shitzer A, Pandolf KB. A physiological strain index to evaluate heat stress. Am J Physiol 1998;275:R129-34.

18 Cleveland WS, Devlin SJ. Locally weighted regression: an approach to regression analysis by local fitting. J Am Stat Assoc 1988;83:596-610.

19 Buller MJ, Latzka WA, Yokota $\mathrm{M}$, et al. A real-time heat strain risk classifier using heart rate and skin temperature. Physiol Meas 2008;29:N79.

20 Baker LB, Lang JA, Kenney WL. Change in body mass accurately and reliably predicts change in body water after endurance exercise. Eur J App/ Physiol 2009;105:959-67.

21 Armstrong LE. Assessing hydration status: the elusive gold standard. J Am Coll Nutr 2007;26:575S-84S.

22 Kavouras SA. Assessing hydration status. Curr Opin Clin Nutr Metab Care 2002;5:519-24

23 Centers for Disease Control and Prevention. Occupational safety and health guidance manual for hazardous waste site activities. US Department of Health and Human Services, 1985

24 Levey AS, Stevens LA, Schmid $\mathrm{CH}$, et al. A new equation to estimate glomerular filtration rate. Ann Intern Med 2009;150:604-12. 
25 World Health Organization. Global database on body mass index. 2012. Glob Database Body Mass Index Geneva, 2012.

26 American Diabetes Association. Diagnosis and classification of diabetes mellitus. Diabetes Care 2010:33:S62-9.

27 Chobanian AV, Bakris GL, Black HR, et al. The seventh report of the joint national committee on prevention, detection, evaluation, and treatment of high blood pressure: the JNC 7 report. JAMA 2003;289:2560-71.

28 Torres $C$, Aragón $A$, González $M$, et al. Decreased kidney function of unknown cause in Nicaragua: a community-based survey. Am J Kidney Dis 2010;55:485-96.

29 Peraza S, Wesseling C, Aragon A, et al. Decreased kidney function among agricultural workers in El Salvador. Am J Kidney Dis 2012;59:531-40.

30 Elinder CG, Wernerson A, Wijkstrom J. Mesoamerican nephropathy (MeN). A "new" chronic kidney disease related to occupational heat exposure with repeated deprivation of salts and water. Int J Nephrol Kidney Fail 2015;1. https://www.sciforschenonline. org/journals/nephrology-kidney/article-data/IJNKF-1-109/IJNKF-1-109.pdf

31 Wesseling C, Crowe J, Hogstedt C, et al. The epidemic of chronic kidney disease of unknown etiology in Mesoamerica: a call for interdisciplinary research and action. Am J Public Health 2013;103:1927-30.

32 Brooks DR, Ramirez-Rubio 0, Amador JJ. CKD in Central America: a hot issue. Am J Kidney Dis 2012;59:481-4.

33 Bandara JM, Senevirathna DM, Dasanayake DM, et al. Chronic renal failure among farm families in cascade irrigation systems in Sri Lanka associated with elevated dietary cadmium levels in rice and freshwater fish (Tilapia). Environ Geochem Health 2008;30:465-78

34 Machiraju R, Yaradi K, Gowrishankar S, et al. Epidemiology of Udhanam endemic nephropathy. J Am Soc Nephrol 2009;20:643A.

35 Clarkson PM. Exertional rhabdomyolysis and acute renal failure in marathon runners. Sports Med 2007;37:361-3.

36 Junglee NA, Di Felice U, Dolci A, et al. Exercising in a hot environment with muscle damage: effects on acute kidney injury biomarkers and kidney function. Am J Physiol 2013;305:F813-20.

37 Schrier R, Henderson H, Tisher C, et al. Nephropathy associated with heat stress and exercise. Ann Intern Med 1967;67:356-76.

38 Crowe J, Nilsson M, Kjellstrom T, et al. Heat-related symptoms in sugarcane harvesters. Am J Ind Med 2015;58:541-8.

39 Kjellstrom T, Crowe J. Climate change, workplace heat exposure, and occupational health and productivity in Central America. Int J Occup Environ Health 2011;17:270-81.

40 Centers for Disease Control. Heat-related deaths among crop workers-United States, 1992-2006. MMWR Morb Mortal Wkly Rep 2008;57:649-53.

41 Arcury TA, Summers P, Talton JW, et al. Heat illness among North Carolina Latino farmworkers. J Occup Environ Med 2015;57:1299-304.

42 Mirabelli MC, Quandt SA, Crain R, et al. Symptoms of heat illness among Latino farm workers in North Carolina. Am J Prev Med 2010;39:468-71.

43 Lam M, Krenz J, Palmandez $P$, et al. Identification of barriers to the prevention and treatment of heat-related illness in Latino farmworkers using activity-oriented, participatory rural appraisal focus group methods. BMC Public Health 2013;13:1004.
44 Bodin T, García-Trabanino R, Weiss I, et al. Intervention to reduce heat stress and improve efficiency among sugarcane workers in El Salvador: Phase 1. Occup Environ Med 2016;73:409-16.

45 Murphy J, Samples J, Morales M, et al. "They talk like that, but we keep working": sexual harassment and sexual assault experiences among Mexican indigenous farmworker women in Oregon. J Immigr Minor Health 2015;17:1834-9.

46 Kim NJE, Vásquez VB, Torres $E$, et al. Breaking the silence: sexual harassment of Mexican women farmworkers. J Agromedicine 2016;21:154-62.

47 Venugopal V, Rekha S, Manikandan K, et al. Heat stress and inadequate sanitary facilities at workplaces - an occupational health concern for women? Glob Health Action 2016;9:31945. http://www.globalhealthaction.net/index.php/gha/article/view/ 31945

48 Fliser D, Laville M, Covic A, et al. A European Renal Best Practice (ERBP) position statement on the Kidney Disease Improving Global Outcomes (KDIGO) Clinical Practice Guidelines on Acute Kidney Injury: Part 1: definitions, conservative management and contrast-induced nephropathy. Nephrol Dial Transplant 2012;27:4263-72.

49 Rubin DK, Perloff JM. Who works for piece rates and why. Am J Agric Econ 1993; 75:1036-43.

50 Toupin D, LeBel L, Dubeau D, et al. Measuring the productivity and physical workload of Brushcutters within the context of a production-based pay system. For Policy Econ 2007;9:1046-55.

51 Lacey RJ, Lewis M, Sim J. Piecework, musculoskeletal pain and the impact of workplace psychosocial factors. Occup Med 2007;57:430-7.

52 McCurdy SA, Samuels SJ, Carroll DJ, et al. Agricultural injury in California migrant Hispanic farm workers. Am J Ind Med 2003;44:225-35.

53 Roquelaure Y, Gabignon Y, Gillant JC, et al. Transient hand paresthesias in Champagne vineyard workers. Am J Ind Med 2001;40:639-45.

54 Wrench J, Lee G. Piecework and industrial accidents: two contemporary case studies. Sociology 1982;16:512-25.

55 Hsu C, McCulloch C, Fan D, et al. Community-based incidence of acute renal failure. Kidney Int 2007;72:208-12.

56 Bellomo R, Kellum JA, Ronco C. Acute kidney injury. Lancet 2012;380:756-66.

57 Hoste EA, Kellum JA, Katz NM, et al. Epidemiology of acute kidney injury. Contrib Nephrol 2010;165:1-8.

58 Roncal-Jimenez C, Lanaspa MA, Jensen T, et al. Mechanisms by which dehydration may lead to chronic kidney disease. Ann Nutr Metab 2015;66:10-13.

59 Johnson RJ, Rodriguez-Iturbe B, Roncal-Jimenez C, et al. Hyperosmolarity drives hypertension and CKD - water and salt revisited. Nat Rev Nephrol 2014;10:415-20. http://www.nature.com/nrneph/journal/vaop/ncurrent/full/nrneph. 2014.76.html?message-global=remove http://dx.doi.org/10.1038/nrneph. 2014.76

60 Varrier M, Ostermann M. Novel risk factors for acute kidney injury. Curr Opin Nephrol Hypertens 2014;23:560-9.

61 Chao CT, Wu VC, Tsai HB, et al. Impact of body mass on outcomes of geriatric postoperative acute kidney injury patients. Shock 2014;41:400-5.

62 Villarejo D, McCurdy SA, Bade B, et al. The health of California's immigrant hired farmworkers. Am J Ind Med 2010;53:387-97. 


\section{Correction: Heat strain, volume depletion and kidney function} in California agricultural workers

Moyce S, Mitchell D, Armitage T, et al. Heat strain, volume depletion and kidney function in California agricultural workers. Occup Environ Med 2017;74:402-409.

The funding statement in this article should include: 'This article was funded by the NIOSH grant R-01 OH010243.'

(C) Article author(s) (or their employer(s) unless otherwise stated in the text of the article) 2018. All rights reserved. No commercial use is permitted unless otherwise expressly granted.

Occup Environ Med 2018;75:162. doi:10.1136/oemed-2016-103848corr1

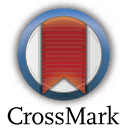

